\title{
INDIKATOR KINERJA JALAN LONG SEGMENT DI BANTEN DENGAN ANALISIS ANALYTICAL HIERARCHY PROCESS
}

\author{
Novel Ridwan', Leksmono S. Putranto
}

\author{
${ }^{1}$ Magister Teknik Sipil, Universitas Tarumanagara Jakarta \\ Email: novel78ridwan.com@gmail.com \\ ${ }^{2}$ Magister Teknik Sipil, Universitas Tarumanagara Jakarta \\ Email: lexyputranto@yahoo.com
}

Masuk: 30-10-2019, revisi: 08-05-2020, diterima untuk diterbitkan: 10-05-2020

\begin{abstract}
ABSTRAK
Panjang jalan Nasional di Provinsi Banten sepanjang 564 kilometer tersebar di beberapa kabupaten dan kota di wilayah Banten. Dalam mengelola implementasi jalan, diperlukan sumber daya yang memadai sehingga tindakan yang cepat dan tepat dapat diambil untuk mengurangi keluhan dari pengguna jalan/masyarakat. Implementasi penanganan jalan yang dilakukan oleh penyedia layanan dengan sistem kontrak konvensional harus dilakukan melalui proses pengadaan yang melewati prosedur berdasarkan hukum dan peraturan yang berlaku, yaitu berdasarkan Surat Edaran Direktur Jenderal Bina Marga No.9/SE/DB Tahun 2015 Implementasi penanganan jalan yang dilakukan oleh penyedia layanan menggunakan Sistem Segmen Panjang. Dalam pelaksanaan penanganan jalan yang dilakukan oleh penyedia jasa dengan sistem kontrak segmen panjang, penyedia jasa harus memenuhi tingkat kondisi layanan jalan, ini agar penyedia jasa mampu memenuhi standar kualitas jalan. Karena manajemen jalan di Provinsi Banten saat ini menggunakan Sistem Segmen Panjang, maka perlu analisis segala aspek dalam penanganan sistem tersebut. Penelitian ini menganalisis aspek-aspek ini dengan pendekatan AHP (Analytical Hierarchy Process yang didasarkan dari wawancara dan kuesioner. Berdasarkan hasil analisis ditemukan dalam pekerjaan long segment pada jalan raya, aspek terpenting yang harus diperhatikan adalah Aspek Drainase, dan pada pekerjaan drainase perlu memperhatikan lancaranya pekerjaan semua jenis saluran yang dibuat dalam pekerjaan drainase.
\end{abstract}

Kata Kunci: Analytical Hierarchy Process (AHP); Jalan Nasional Provinsi Banten; Sistem ruas panjang

\begin{abstract}
The length of National roads in Banten Province along 564 kilometers is spread in several regencies and cities in the Banten region. In managing road implementation, adequate resources are needed so that prompt and appropriate action can be taken to reduce complaints from road users / communities. Implementation of road handling carried out by service providers with a conventional contract system must be done through a procurement process that goes through procedures based on applicable laws and regulations, namely based on Circular Letter of the Director General of Highways No.9 / SE / DB 2015 Implementation of road handling carried out by service providers use the Long Segment System. In the implementation of road handling carried out by service providers with a long segment contract system, service providers must meet the level of road service conditions, so that service providers are able to meet road quality standards. Because road management in Banten Province currently uses the Long Segment System, it is necessary to analyze all aspects of handling the system. This study analyzes these aspects with the AHP (Analytical Hierarchy Process approach based on interviews and questionnaires. Based on the results of the analysis found in long segment work on the highway, the most important aspect to consider is the Drainage Aspect, and the drainage work needs to pay attention to the smooth work all types of channels made in drainage work.
\end{abstract}

Keywords: Analytical Hierarchy Process (AHP); Banten Province National Road; Long section system 


\section{PENDAHULUAN}

\section{Latar Belakang}

Jalan merupakan salah satu prasarana penting dalam menunjang perkembangan ekonomi maupun kesejahteraan masyarakat setempat. Di kota-kota besar pada umumnya telah tersedia banyak jalan yang baik. Namun karena jalan mempunyai karakteristik selalu mengalami penurunan kualitas, baik jalan tersebut digunakan maupun tidak, maka untuk mempertahankan kualitas jalan agar tetap baik atau minimal mengurangi penurunan kualitas, perlu dilakukan pemeliharan. Sementara dalam Undang-undang No.22 Tahun 2009 pasal 24 tentang Lalu Lintas dan Angkutan Jalan mengamanatkan :

a. Penyelenggara jalan wajib segera dan patut untuk memperbaiki jalan yang merusak yang dapat mengakibatkan kecelakaan lalu lintas;

b. Dalam hal belum dapat dilakukan perbaikan jalan yang rusak sebagaimana dimaksud pada ayat (1), penyelenggara jalan wajib memberi tanda atau rambu pada jalan yang rusak untuk mencegah terjadinya kecelakaan lalu lintas.

Dalam mengelola penyelengaraan jalan diperlukan sumber daya yang memadai agar dapat dilakukan tindakan yang cepat dan tepat, sehingga tidak terjadi keluhan dari pengguna jalan/ masyarakat. Sementara pelaksanaan penanganan jalan yang dilaksanakan oleh penyedia jasa dengan sistem kontrak konvensional, harus dilaksanakan melalui proses pengadaan yang melewati prosedur berdasarkan peraturan dan perundangan yang berlaku serta memerlukan waktu yang cukup panjang kecuali penanganan bencana alam atau pekerjaan darurat.

Di Provinsi Banten mulai menerapkan pekerjaan long segment berdasarkan indikator kenerja jalan pada tahun 2016. Berdasarkan Surat Edaran Direktorat Jenderal Bina Marga No.9/SE/DB Tahun 2015 Pelaksanaan penanganan jalan yang dilakukan oleh penyedia jasa dengan sistim long segment.

Sistim long segment merupakan penanganan Preservasi Jalan dalam batasan satu panjang segmen yang menerus dilaksanakan dengan tujuan untuk mendapatkan kondisi jalan mantap dan standar sepanjang segmen. Dengan akan diterapkannya pelaksanaan penanganan long segment berdasarkan kinerja jalan maka perlu dianalisis aspek-aspek yang mempengaruhi pelaksanaan di Provinsi Banten.

\section{Rumusan Masalah}

Berdasarkan dari uraian latar belakang di atas, maka rumusan masalah dalam penelitian yang terkait dengan metode AHP dirumuskan sebagai berikut:

a. Bagaimanakah kriteria yang dipertimbangkan dalam indikator kinerja jalan pada pelakasanaan long segment di Provinsi Banten ?

b. Bagaimanakah urutan prioritas indikator kinerja jalan pada pelakasanaan long segment di Provinsi Banten?

\section{METODE PENELITIAN}

\section{Gambaran Umum Penelitian}

Data dalam penelitian ini di peroleh dari hasil kuesioner yang disebarkan pada 30 responden setelah itu dilanjutkan dengan analisis untuk menemukan aspek dan kriteria yang menjadi prioritas penanganan dalam indikator kinerja jalan dalam pelaksanaan pekerjaan long segment di Provinsi Banten, maka ditentukan Aspek, Kriteria dan Alternatif untuk dijadikan butir-butir 
pertanyaan yang akan diukur dalam bentuk kuesioner. Selanjutnya dari hasil kuesioner akan dianalisis untuk mendapatkan bobot aspek dan kriteria .

\section{Lokasi Penelitian}

Penelitian ini dilakukan pada proyek-proyek paket pekerjaan jalan long segment yang ada di Provinsi Banten yang berfungsi sebagai jalur strategis yang menghubungkan antar Kabupaten dan kota di wilayah tersebut.

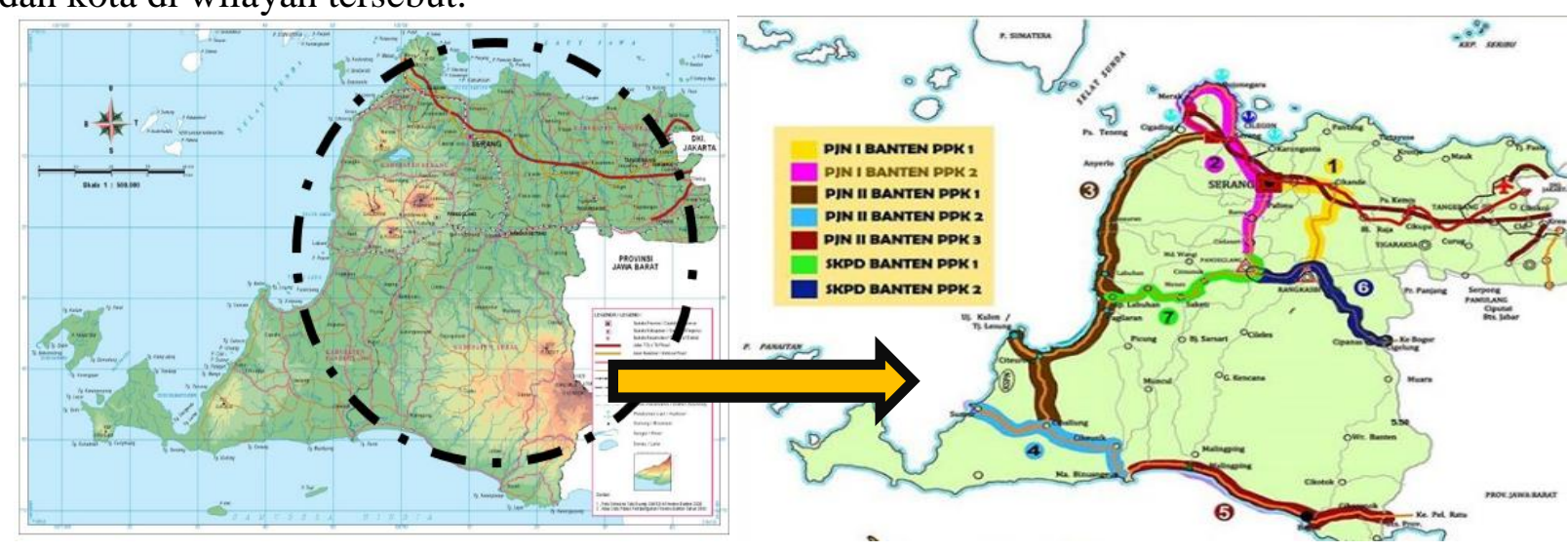

Gambar Error! No text of specified style in document.. Ruas Jalan Nasional Provinsi Banten

Keterangan :

: Ruas Serang - Cikande - Rangkasbitung

: Ruas Serang - Cilegon - Bojonegara - Merak

: Ruas Cilegon - Pasauran - Citeurep

: Ruas Cibaliung - Sumur

: Ruas Cikeusik - Bayah - Bts. Jabar

: Ruas Pandeglang - Saketi - Sp. Labuan

: Ruas Serang - Pandeglang - Cigelung

\section{Responden Penelitian}

Responden penelitian adalah orang-orang pengambil kebijakan/ keputusan sekaligus mengetahui dan terlibat didalam kegiatan proyek-proyek paket pekerjaan jalan long segment di Provinsi Banten dan masyarakat sebagai pengguna jalan dalam hal ini pihak Kecamatan atau kelurahan yang dilalui paket tersebut, yaitu sebanyak 30 orang yang diambil dari:

Tabel Error! No text of specified style in document.. Jumlah Responden

\begin{tabular}{clc}
\hline No. & \multicolumn{1}{c}{ Uraian } & Responden \\
\hline 1 & Sub. Dit Preservasi Bina Marga & 1 \\
\hline 2 & Ka. Bid I BBPJN VI & 1 \\
\hline 3 & Kepala Satker PJN Provinsi Banten & 4 \\
\hline 4 & PPK Pelaksanaan Jalan Nasional di Provinsi Banten & 7 \\
\hline 5 & Konsultan Supervisi Paket pekerjaan Long Segment & 7 \\
\hline 6 & Kontraktor Pelaksanaa Paket pekerjaan Long Segment & 3 \\
\hline 7 & Kecamatan atau kelurahan yang dilintasi paket pekerjaan long segment & $\mathbf{3 0}$ \\
\hline & Total
\end{tabular}

\section{Variabel Penelitian}

Definisi variabel penelitian dan definisinya dilakukan dengan tujuan untuk mengidentifikasi variabel/ Aspek dan kriteria yang dipertimbangkan dalam penentuan pengalokasian dana untuk 
alternatif pemeliharaan ruas jalan di Provinsi Banten. Sesuai dengan tujuan penelitian, maka identifikasi variabel/aspek penelitian serta definisinya dalam penelitian ini dapat dilihat dalam Tabel di bawah sebagaimana berikut :

Tabel 1. Variabel Penelitian dan Definisinya Variabel/ Aspek Definisi

\begin{tabular}{cl}
\hline Aspek & \multicolumn{1}{c}{ Penjelasan / Definisi } \\
\hline & Pekerjaan perkerasan jalan bertujuan untuk memliharan kerataan permukaan jalur lalu \\
& lintas, mencakup retak struktural atau retak kecil yang menjalar, penambalan lubang \\
& lubang (patching), perataan setempat (spot leveling), perbaikan tipe perkerasan, \\
perbaikan retak, perbaikan permukaan yang bergelombang atau keriting, dan meratakan \\
Perkerasan & alur yang dalam untuk mempertahankan lereng melintang jalan yang standar. Pekerjaan \\
Jalan & pemeliharaan kinerja perkerasan ini juga untuk mengembalikan kondisi struktural \\
(A) & perkerasan jika dipandang sebagai bagian dari pekerjaan perbaikan untuk memenuhi \\
& Indikator Kinerja Jalan yang disyaratkan dan untuk mencegah kerusakan yang lebih \\
& besar sehingga perkerasan jalan dapat berfungsi dengan baik. (Spesifikasi Umum 2018 \\
& KemenPUPR)
\end{tabular}

Aspek

Bahu Jalan

(B)

Drainase

(C)

\begin{tabular}{c}
\hline \\
Perlengkapan \\
Jalan
\end{tabular}

(D)

Pelengkap

(E)

\begin{tabular}{c}
\hline \\
Pengendalian \\
Tanaman
\end{tabular}

(F)

\section{Penjelasan / Definisi}

Pekerjaan pemeliharaan bahu jalan bertujuan untuk memelihara atau memperbaiki permukaan bahu jalan eksisting sehingga kemiringannya tetap konsisten sesuai dengan ketentuan sebagaimana yang disyaratkan, seperti pengisian lubang, pemotongan dan perataan, pembuangan tanaman liar atau rumput, semak - semak dan benda lainnya sehingga bahu jalan dapat berfungsi dengan baik sebagaimana sesia dengan indikator kinerja yang disyaratkan. (Spesifikasi Umum 2018 KemenPUPR)

Pekerjaan pemeliharaan kinerja drainase jalan bertujuan agar sistem drainase jalan eksisting berfungsi dengan baik dan lancar pada lokasi yang termasuk dalam cakupan pekerjaan drainase antara lain saluran samping, saluran melintang, saluran pembuangan (outlet/inlet) dan bak kontrol serta semua sistem drainase yang terkait dengan pekerjaan ruas jalan dalam kontrak. (Spesifikasi Umum 2018 KemenPUPR)

Pekerjaan pemeliharaan kinerja perlengkapan jalan bertujuan supaya perlengkapan jalan eksisting dapat dibaca dengan jelas oleh pengguna jalan atau reflektifitas rambu terjaga dan berfungsi dengan baik. Pekerjaan ini mencakup kegiatan seperti pembersihan dan perbaikan rambu jalan, patok pengarah dan patok kilometer, rel pengaman, pengecatan kembali huruf yang sudah tak terbaca pada rambu jalan dan pengecatan kerb, median, marka jalan yang sudah tidak terlihat dengan jelas serta pengendalian tumbuh - tumbuhan atau penebangan pohon yang menghalangi jarak pandang atau jika membahayakan keselamatan lalu lintas termasuk pembuangan akar akarnya. (Spesifikasi Umum 2018 KemenPUPR)

Pekerjaan pemeliharaan kinerja bangunan pelengkap jalan bertujuan untuk mencegah kerusakan yang lebih besar pada bangunan pelengkap jalan eksisting seperti tembok penahan tanah, trotoar, pulau jalan dan fasilitas penyebrangan pejalan kaki dan jembatan dapat berfungsi menurut jenisnya. (Spesifikasi Umum 2018 KemenPUPR)

Pekerjaan pemeliharaan pengendalian tanaman yaitu membersihkan lokasi sepanjang ruas jalan bebas dari tanaman disekitar ujung gorong-gorong, terusan gorong-gorong, selokan air, sekitar rambu, guarddrails, patok pengarah, tiang lampu, bahu jalan, seluruh permukaan yang dilabur, bangunan bawah jembatan dan deck jembatan. Pada daerah timbunan dan galian jalan mencakup pemotongan rumput, semak - semak dan pohon-pohon kecil yang tingginya sudah mencapai lebih dari $10 \mathrm{~cm}$ dan/atau untuk memperbaiki penampilan di dalam atau di samping jalan yang dibangun atau memperbaiki jarak pandang pada tikungan selama periode pelaksanaan dan pekerjaan lain yang mencakup perbaikan lereng yang tidak stabil. (Spesifikasi Umum 2018 KemenPUPR) 


\title{
Aspek dan Kriteria Penelitian
}

Untuk memperoleh data, maka dibuat pertanyaan-pertanyaan yang dihubungkan dengan variabel/aspek tersebut dengan kriterianya masing-masing, seperti yang terlihat pada tabel di bawah.

Tabel 3. Aspek dan Kriteria Penelitian

\begin{tabular}{|c|c|}
\hline Aspek & Kriteria \\
\hline \multirow{6}{*}{$\begin{array}{l}\text { Perkerasan Jalan } \\
\text { (A) }\end{array}$} & Lubang (A1) \\
\hline & Retakan (A2) \\
\hline & Amblas (A3) \\
\hline & Patahan (untuk rigid) $(\mathrm{A} 4)$ \\
\hline & Joint Sealent (untuk rigid) (A5) \\
\hline & Kerataan (overlay) (A6) \\
\hline \multirow{3}{*}{$\begin{array}{l}\text { Bahu Jalan } \\
\text { (B) }\end{array}$} & Lubang (B1) \\
\hline & Elevasi / Ketinggian (B2) \\
\hline & Amblas (B3) \\
\hline \multirow{2}{*}{$\begin{array}{l}\text { Drainase } \\
(\mathrm{C})\end{array}$} & Semua Jenis Saluran $(\mathrm{C} 1)$ \\
\hline & Lereng Timbunan dan Galian (C2) \\
\hline \multirow{3}{*}{$\begin{array}{l}\text { Perlengkapan Jalan } \\
\text { (D) }\end{array}$} & Rambu Peringatan dan Rambu Petunjuk (D1) \\
\hline & Pemisah Horizontal pada Median atau Trotoar (D2) \\
\hline & Pagar Keselamatan Jalan (D3) \\
\hline \multirow{4}{*}{$\begin{array}{l}\text { Bangunan Pelengkap } \\
\text { (E) }\end{array}$} & Jalan Pendekat (Oprit) (E1) \\
\hline & Dinding Penahan Tanah (E2) \\
\hline & Expansion Joint (Jembatan pada jalan) (E3) \\
\hline & Pagar Jembatan $($ Span $\leq 6.0 \mathrm{~m})(\mathrm{E} 4)$ \\
\hline \multirow{2}{*}{$\begin{array}{l}\text { Pengendalian Tanaman } \\
\text { (F) }\end{array}$} & Bebas dari tumbuh-tumbuhan di sekitar (F1) \\
\hline & Ketinggian Tumbuh tumbuhan (F2) \\
\hline
\end{tabular}

\section{Data Penelitian}

Data penelitian yang digunakan adalah data primer yang merupakan pertanyaan (kuesioner) dalam bentuk angket dibuat untuk memperoleh data-data primer yang disusun berdasarkan parameter-parameter analisis yang dibutuhkan dan relevan sesuai dengan maksud dan tujuan dari penelitian ini yang ditujukan kepada responden yang sudah ditentukan sebelumnya

\begin{abstract}
Analisis Data
Data yang diperoleh dari hasil survei (kuesioner) nantinya diolah untuk memperoleh informasi dalam bentuk tabel. Hasil olahan data tersebut digunakan menjawab pertanyaan pada rumusan masalah. Pengolahan data hendaknya memperhatikan jenis data yang dikumpulkan dengan berorientrasi pada tujuan yang hendak dicapai. Ketepatan dalam teknik analisis sangat mempengaruhi ketepatan hasil penelitian. Adapun teknik analisis data yang digunakan adalah metode AHP dengan Expert Choice 21.
\end{abstract}

\section{AHP (Analytic Hierarchy Process)}

Metode AHP merupakan suatu metode pengambilan keputusan yang menstruktur masalah yang kompleks dalam sebuah hirarki yang terdiri dari beberapa tingkatan yang memuat tujuan, beberapa aspek dan atau kriteria pertimbangan serta sejumlah alternatif pemecahan. Aspekaspek, riteria-kriteria, dan alternatif-alternatif inilah yang selanjutnya disebut sebagai elemenelemen keputusan. Elemen-elemen ini dibandingkan satu sama lain secara berpasangan dan bobot prioritas relatifnya masing-masing ditentukan untuk mendapatkan prioritas menyeluruh sebagai hasil akhir dari AHP. 
Saaty (1993) mengatakan bahwa AHP adalah suatu prosedur pengambilan keputusan multi kriteria yang terstruktur. Metode ini pertama kali dikembangkan oleh Thomas L. Saaty, seorang matematikawan dari University of Pittsburgh Amerika Serikat,pada tahun 1970-an. AHP merupakan model yang luwes yang memungkinkan kita mengambil keputusan yang mengkombinasikan pertimbangan dan nilai-nilai pribadi secara logis. AHP digunakan untuk mengkaji permasalahan yang dimulai dengan mendefinisikan permasalahan tersebut secara seksama kemudian menyusunnya kedalam sebuah hirarki yang terdiri dari beberapa tingkat/level, yaitu level tujuan, kriteria dan alternatif. Setelah menyusun hirarki, selanjutnya adalah memberi nilai numerik pada pertimbangan subyektif tentang tingkat preferensi antar elemen pada setiap level hirarki. Hasil akhir dari AHP adalah prioritas bagi alternatir - alternatif yang ada untuk memenuhi tujuan dari permasalahan yang dihadapi (Saaty, 1993).

Prinsip Kerja AHP (Marimin, 2004) adalah penyederhanaan suatu persoalan kompleks yang tidak terstruktur, stratejik, dan dinamik menjadi bagian bagiannya serta menata dalam suatu hirarki. Kemudian tingkat kepentingan setiap variabel diberi nilai numerik secara subjektif tentang arti penting variabel tersebut secara relatif dibandingkan dengan variabel lain. Dari berbagai pertimbangan tersebut kemudian dilakukan sintesa untuk menetapkan variabel yang memiliki prioritas tinggi dan berperan untuk mempengaruhi hasil pada sistem tersebut. Secara grafis, persolaan keputusan AHP dapat dikonstruksikan sebagai diagram bertingkat, yang dimulai dengan goal/ sasaran, lalu aspek level pertama, kriteria dan akhirnya alternatif. AHP memungkinkan pengguna untuk memberi nilai bobot relatif dari suatu kriteria majemuk (atau alternatif mejemuk terhadap suatu kriteria) secara intuitif, yaitu dengan melakukan perbandingan berpasangan (pairwise comparisons).

AHP memiliki banyak keunggulan dalam menjelaskan proses pengambilan keputusan, karena dapat digambarkan secara grafis, sehingga mudah dipahami oleh semua pihak yang terlibat dalam pengambilan keputusan. Dengan AHP proses keputusan kompleks dapat diuraikan menjadi keputusan keputusan lebih kecil yang dapat ditangani dengan mudah. Selain itu AHP juga menguji konsistensi penilaian, bila terjadi penyimpangan yang terlalu besar dari konsistensi sempurna, maka hal ini menunjukan bahwa penilaian perlu diperbaiki, atau hierarki harus distruktur ulang.

Beberapa keuntungan yang diperoleh bila memecahkan persoalan dan mengambil keputusan dengan menggunakan AHP adalah (Marimin, 2004):

a. Kompleksitas: AHP memadukan langkah-langkah deduktif dan langkah-langkah yang berdasarkan sistem dalam memecahkan persoalan kompleks.

b. Saling Ketergantungan: AHP dapat menangani saling ketergantungan elemen-elemen dalam suatu sistem dan tidak memaksakan pemikiran linier.

c. Penyusunan Hirarki: AHP mencerminkan kecendrungan alami pikiran untuk memilah-milah elemen-elemen suatu sistem dalam berbagai tingkat berlainan dan mengelompokkan unsur yang serupa dalam setiap tingkat.

d. Konsistensi: AHP melacak konsistensi logis dari pertimbangan-pertimbangan yang digunakan untuk menetapkan berbagai prioritas.

e. Penilaian dan Konsensus: AHP tidak memaksakan konsensus tetapi mensintesiskan suatu hasil yang representatif dari berbagai penilaian yang berbeda.

f. Pengulangan Proses: AHP memungkinkan organisasi memperhalus definisi mereka pada suatu persoalan dan memperbaiki pertimbangan dan pengertian mereka melalui pengulangan. 


\section{HASIL DAN PEMBAHASAN}

\section{Pemeliharaan Prasarana Jalan}

Jalan raya adalah salah satu prasarana yang akan mempercepat pertumbuhan dan pengembangan suatu daerah serta akan membuka hubungan sosial, ekonomi dan budaya antar daerah. Kalan sebagai bagian sistem transportasi nasional mempunyai peranan penting terutama dalam mendukung bidang ekonomi, sosial dan budaya serta lingkungan (Undang-Undang Republik Indonesia No. 38 tahun 2004 Tentang Jalan). Maka jalan ini sangatlah dibutuhkan oleh masyarakat di dalam melaksanakan aktivitas sehari-hari. Setelah jalan raya dibuka dan dilalui beban lalu lintas, tingkat pelayanan jalan akan mengalami penurunan fungsi dan struktur sampai batas minimum yang bisa diterima. Menurunnya tingkat pelayanan jalan ditandai dengan adanya kerusakan pada lapisan perkerasan jalan, kerusakan yang terjadi juga bervariasi di setiap segmen jalan. Penyebab utama kerusakan jalan secara umum dapat dikatakan antara lain: beban kendaraan yang berlebih (overloading), mutu pelaksanaan pekerjaan yang tidak sesuai, drainase yang tidak/ kurang berfungsi dan perencanaan yang tidak tepat. Selain itu minimnya biaya pemeliharaan jalan, keterlambatan pengeluaran anggaran serta prioritas penanganan yang kurang tepat juga menjadi penyebab (Muis, 2010).

\section{Pemeliharaan Rutin}

Pemeliharaan rutin merupakan kegiatan merawat serta memperbaiki kerusakan kerusakan yang terjadi pada ruas-ruas jalan dengan kondisi pelayanan mantap. Pemeliharaan rutin hanya diberikan terhadap lapis permukaan yang sifatnya untuk meningkatkan kualitas berkendaraan (riding quality), tanpa meningkatkan kekuatan struktural dan dilakukan sepanjang tahun.

\section{Pemeliharaan Berkala}

Pemeliharaan berkala merupakan kegiatan penanganan terhadap setiap kerusakan yang diperhitungkan dalam desain agar penurunan kondisi jalan dapat dikembalikan pada kondisi kemantapan sesuai dengan rencana. Pemeliharaan berkala dilakukan terhadap jalan pada waktuwaktu tertentu (tidak menerus sepanjang tahun) dan sifatnya meningkatkan kemampuan struktural.

\section{Rehabilitasi}

Rehabilitasi merupakan kegiatan penanganan terhadap setiap kerusakan yang tidak diperhitungkan dalam desain, yang berakibat menurunnya kondisi kemantapan pada bagian/tempat tertentu dari suatu ruas jalan dengan kondisi rusak ringan, agar penurunan kondisi kemantapan tersebut dapat ikembalikan pada kondisi kemantapan sesuai dengan rencana.

\section{Peningkatan Jalan}

Peningkatan jalan merupakan penanganan jalan guna memperbaiki pelayanan jalan yang berupa peningkatan struktural dan atau geometriknya agar mencapai tingkat pelayanan yang direncanakan atau dengan kata lain, peningkatan jalan dilakukan untuk memperbaiki kondisi jalan dengan kemampuan tidak mantap atau kritis menjadi jalan dengan kondisi mantap.

\section{Struktur Hierarki}

Hirarki fungsional sangat membantu untuk membawa sistim ke arah tujuan yang diinginkan. Dalam penelitian ini hirarki yang digunakan adalah hirarki fungsional. 
Hirarki yang terbentuk terdiri dari tiga tingkat yaitu:

a. Level pertama adalah tujuan, untuk mengidentifikasi variabel/Aspek dan kriteria prioritas penanganan dalam indikator kinerja jalan dalam pelaksanaan pekerjaan long segment

b. Level kedua adalah Aspek, terdapat enam macam aspek, yaitu :

- Perkerasan Jalan (A),

- Bahu Jalan (B),

- Drainase (C),

- Perlengkapan Jalan (D),

- Bangunan Pelengkap (E),

- Pengendalian Tanaman $(\mathrm{F})$.

c. Level ketiga adalah Kriteria, yaitu :

- Lubang (A1)

- Retakan (A2)

- Amblas (A3)

- Faulting (untuk perkeraan beton semen) (A4)

- Joint Sealent (untuk perkerasan beton semen) (A5)

- Ketidakrataan (untuk perkerasan yang dilaksanakan pelapisan ulang/overlay) (A6)

- Amplitudo Keriting/Corrugation (untuk jalan tanpa penutup aspal) (A7)

- Kedalaman Alur/Rutting (untuk jalan tanpa penutup aspal) (A8)

- Lubang (untuk jalur lalin berpenutup aspal) (B1)

- Elevasi / Ketinggian (untuk jalur lalin berpenutup aspal) (B2)

- Amblas (untuk jalur lalin berpenutup aspal) (B3)

- Joint Sealent (untuk perkerasan beton semen) (B4)

- Kebersihan permukaan bahu jalan (untuk jalur lalin tanpa penutup) (B5)

- Semua Jenis Saluran (C1),

- Lereng Timbunan dan Galian (C2),

- Rambu Peringatan dan Rambu Petunjuk (D1),

- Pemisah Horizontal pada Median atau Trotoar (D2),

- Pagar Keselamatan Jalan (D3),

- Jalan Pendekat (Oprit) (E1),

- Dinding Penahan Tanah (E2),

- Bebas dari tumbuh-tumbuhan di sekitar (F1),

- Ketinggian Tumbuh tumbuhan (F2).

\section{Penentuan Prioritas Dengan Expert Choice}

Ada enam kriteria yang yang dijadikan faktor pertimbangan perbaikan ruas jalan, yaitu: Perkerasan Jalan, Bahu Jalan, Drainase, Perlengkapan Jalan, Bangunan Pelengkap, Pengendalian Tanaman. Dari data hasil penelitian selanjutnya dihitung bobot kriteria. Dengan menggunakan software Expert Choice, diperoleh hasil bobot dan nilai Consistency Ratio masing-masing kriteria dan sub kriteria adalah sebagai berikut: 
Penilaian Kombinasi Untuk N = 30 Responden terhadap Goal/ Penelitian: Prioritas Aspek Pekerjaan Long Segment Jalan Raya Provinsi Banten.

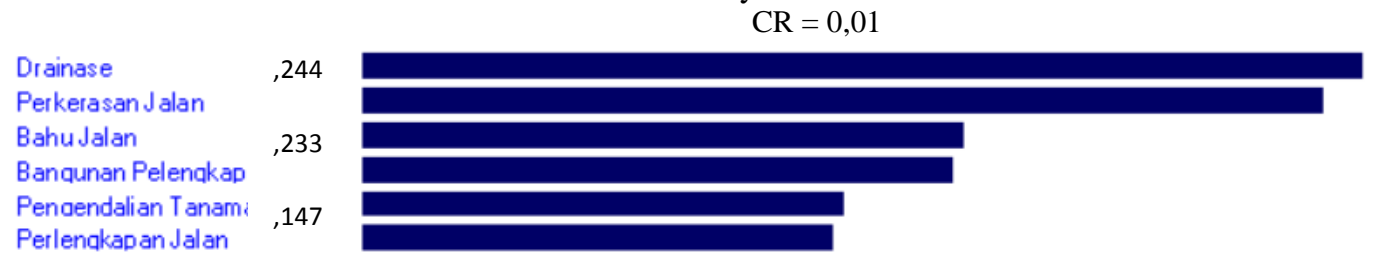

Gambar Error! No text of specified style in document.. Bobot dan Nilai Consistency Ratio untuk Matrik Banding Berpasangan Antar Aspek

Berdasarkan gambar di atas, dari hasil analisis AHP, menunjukkan nilai Consistency Ratio (CR) sebesar 0,01, berarti matrik dari kriteria tersebut dikatakan konsisten, karena nilai CR $<10 \%$. Disisi lain, diketahui pula bahwa kriteria Aspek Drainase memiliki bobot terbesar yaitu 0,244 atau 24,1\%. Dalam hal ini Pemeliharaan drainase jalan penting untuk menjamin keselamatan dan umur rencana jalan dengan cara mencegah erosi jalan, mencegah kejenuhan subbase dan Mencegah kerusakan struktur jalan. Posisi kedua ditempati oleh kriteria Aspek Perkerasan Jalan sebesar 0,233 (23,3\%), diposisi ketiga diduduki kriteria Aspek Bahu Jalan sebesar 0,147 $(14,7 \%)$, dan yang berikutnya adalah kriteria Aspek Bangunan Pelengkap sebesar 0,144 (14,4 $\%)$, Kriteria Aspek Pengendalian Tanaman sebesar 0,117 (11,7\%) dan yang terakhir kriteria Aspek Perlengkapan Jalan sebesar 0,115 (11,5\%) Bagian - bagian perlengkapan jalan seperti rambu jalan, patok pengarah dan patok kilometer dapat berfungsi dengan baik sehingga dapat dilihat dengan jelas oleh pengguna jalan.

\section{Pembobotan dan Penentuan Konsistensi Kriteria Aspek}

\section{A. Aspek Perkerasan Jalan}

Ada delapan sub kriteria yang terdapat pada kriteria Aspek Perkerasan Jalan. Kedelapan sub kriteria tersebut merupakan faktor-faktor yang mempengaruhi pemilihan alternatif perkerasan jaringan jalan di Provinsi Banten. Kedelapan item tersebut adalah Lubang (A1), Retakan (A2), Amblas (A3), Faulting (untuk perkeraan beton semen) (A4), Joint Sealent (untuk perkerasan beton semen) (A5), Ketidakrataan (untuk perkerasan yang dilaksanakan pelapisan ulang/overlay) (A6), Amplitudo Keriting/Corrugation (untuk jalan tanpa penutup aspal) (A7), Kedalaman Alur/Rutting (untuk jalan tanpa penutup aspal) (A8), Selanjutnya dihitung bobot tiap sub kriteria menggunakan bantuan software Expert Choise dan dihasilkan bobot sebagai berikut:

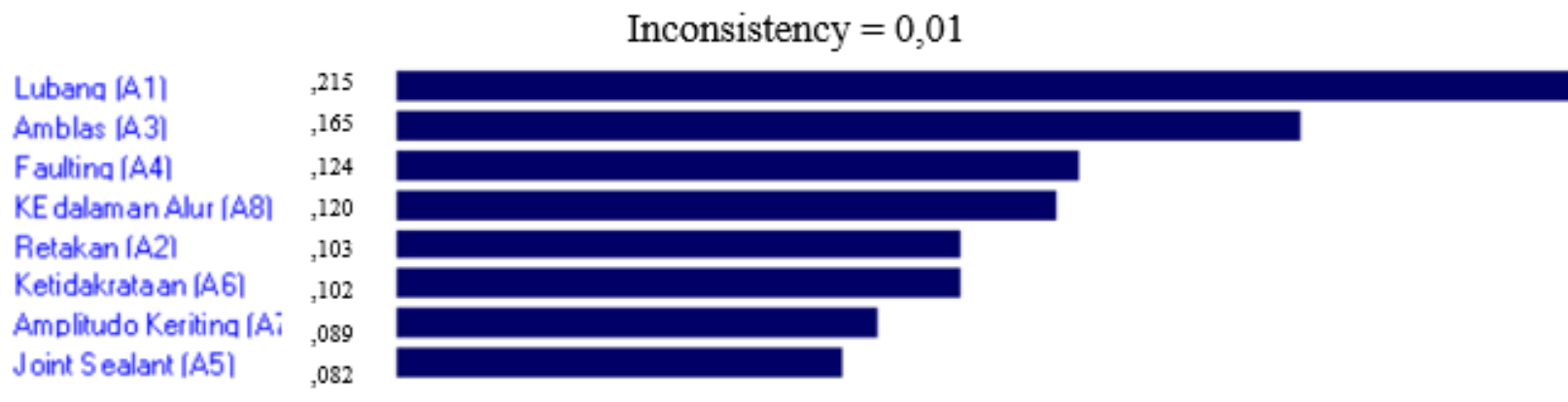

Gambar 3. Bobot dan Nilai Consistency Ratio Untuk Kriteria Aspek Perkerasan Jalan

Berdasarkan gambar di atas, dari hasil analisis AHP dapatkan nilai CR 0,02, berarti matrik dari kriteria tersebut dikatakan konsisten, karena nilai CR $<10 \%$. Selain itu, pada Gambar IV.3 juga diketahui bahwa kriteria Lubang memiliki bobot terbesar yaitu sebesar 0,215 (21,5\%). Dalam hal ini pekerjaan perkersan jalan pada penanganan lubang sangat penting untuk pengembalian 
kondisi struktural perkerasan jika dipandang sebagian bagian dari pekerjaan perbaikan untuk memenuhi indikator kinerja jalan yang di syaratkan dan untuk mencegah kerusakan yang lebih besar sehingga perkerasan jalan dapat berfungsi lebih baik (Spesifikasi Umum 2018 KemenPUPR) . Kriteria untuk Joint Sealant memiliki bobot terkecil yaitu sebesar 0,082 (8,2 \%) dibandingkan kedelapan anak kriteria lainnya karena merupakan pekerjaan pemeliharaan yang bersifat preventitif pada perkerasan jalan.

\section{B. Aspek Bahu Jalan}

Terdapat lima sub kriteria dalam aspek Bahu Jalan. Kelima sub kriteria tersebut mempengaruhi pemilihan alternatif penanganan perkerasan bahu Jalan di Provinsi Banten. Kelima item tersebut adalah Lubang (untuk jalur lalin berpenutup aspal) (B1), Elevasi / Ketinggian (untuk jalur lalin berpenutup aspal) (B2), Amblas (untuk jalur lalin berpenutup aspal) (B3), Joint Sealent (untuk perkerasan beton semen) (B4), Kebersihan permukaan bahu jalan (untuk jalur lalin tanpa penutup) (B5). Selanjutnya dihitung bobot tiap sub kriteria menggunakan bantuan software Expert Choise dan dihasilkan bobot sebagai berikut:

$\begin{array}{ll}\text { Amblas [B3] } & , 269 \\ \text { Elevasi/Ketinqqian [B2] } & , 217 \\ \text { Joint Sealant (B4] } & , 195 \\ \text { Lubanq di Bahu [B1] } & , 161 \\ \text { Kebersihan Permukaan Bahu Jalan IB5 } & , 158\end{array}$

Inconsistency $=0,01$

Gambar 4. Bobot dan Nilai Consistency Ratio Untuk Kriteria Aspek Bahu Jalan

Berdasarkan gambar di atas, Dari hasil analisis AHP Nilai CR (Pada Lampiran 3) bobot dan nilai consistency ratio untuk matrix banding berpasangan untuk sub kriteria berdasarkan kriteria aspek Bahu Jalan didapatkan nilai CR 0,01, berarti matrik dari kriteria tersebut dikatakan konsisten, karena nilai CR < 10\%. Gambar IV.5 juga menunjukkan bahwa kriteria Amblas memiliki bobot tertiggi dibandingkan anak kriteria lainnya yaitu sebesar 0,269 (26,9\%).Dalam hal ini Ambalas pada bahu jalan merupakan bagian pekerjaan pemeliharaan untuk memelihara atau memepebaiki permukaan bahu jalan sehingga kemiringannya tetap konsisten sesuai dengan ketentuan yang di syaratkan.

\section{Aspek Drainase}

Terdapat dua sub kriteria dalam aspek Drainase. Kedua sub kriteria tersebut mempengaruhi pemilihan alternatif penanganan perkerasan Jalan di Provinsi Banten. Kedua item tersebut adalah Semua Jenis Saluran (C1), Lereng Timbunan dan Galian (C2). Selanjutnya dihitung bobot tiap sub kriteria menggunakan bantuan software Expert Choise dan dihasilkan bobot sebagai berikut:

$$
\text { Inconsistency }=0,0
$$

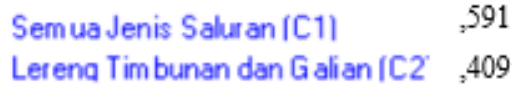

Gambar 5. Bobot dan Nilai Consistency Ratio Untuk Kriteria Aspek Drainase

Berdasarkan gambar di atas, dari hasil analisis AHP Nilai CR (Pada Lampiran 3) bobot dan nilai consistency ratio untuk matrix banding berpasangan untuk sub kriteria berdasarkan kriteria aspek Drainase didapatkan nilai CR 0,00, berarti matrik dari kriteria tersebut dikatakan konsisten, karena nilai CR $<10 \%$. Gambar IV.7 juga menunjukkan bahwa anak kriteria "Semua Jenis 
Saluran" memiliki bobot tertiggi dibandingkan anak kriteria lainnya yaitu sebesar 0,591 $(59,1 \%)$.Pekerjaan pemeliharaan kinerja drainase jalan bertujuan agar sistem drainase jalan eksisting berfungsi dan lancar pada lokasi yang termasuk dalam cakupan pekerjaan saluran pembuang (outlet dan inlet) dan bak kontrol berfungsi dengan baik.

\section{Aspek Perlengkapan Jalan}

Terdapat tiga sub kriteria dalam aspek Perlengkapan Jalan. Ketiga sub kriteria tersebut mempengaruhi pemilihan alternatif penanganan perkerasan Jalan di Provinsi Banten. Ketiga item tersebut adalah Rambu Peringatan dan Rambu Petunjuk (D1), Pemisah Horizontal pada Median atau Trotoar (D2), Pagar Keselamatan Jalan (D3). Selanjutnya dihitung bobot tiap sub kriteria menggunakan bantuan software Expert Choise dan dihasilkan bobot sebagai berikut:

$$
\text { Inconsistency }=0,03
$$

Paqar Keselamatan Jalan [D3]

Rambu Peringatan dan Rambu Petuniuk [D1]

Pem is ah Horizontal Pada Median atau Trotoar ID2

353
331
316

Gambar 6. Bobot dan Nilai Consistency Ratio Untuk Kriteria Aspek Perlengkapan Jalan

Berdasarkan gambar di atas, dari hasil analisis AHP Nilai CR (Pada Lampiran 3) bobot dan nilai consistency ratio untuk matrix banding berpasangan untuk sub kriteria berdasarkan kriteria aspek Perlengkapan Jalan didapatkan nilai CR 0,03, berarti matrik dari kriteria tersebut dikatakan konsisten, karena nilai CR $<10 \%$. Gambar IV.9 juga menunjukkan bahwa anak kriteria " Pagar Keselamatan Jalan" memiliki bobot tertiggi dibandingkan anak kriteria lainnya yaitu sebesar 0,353 (35,3\%).Pekerjaan pemeliharaan kinerja perlengkapan jalan bertujuan supaya perlengkapan jalan eksisting dapat di baca dengan jelas oleh pengguna jalan.pekerjaan ini mencakup kegiatan pembersihan dan perbaikan rambu jalan dan patok kilometer

\section{E. Aspek Bangunan Pelengkap}

Terdapat dua sub kriteria dalam aspek Bangunan Pelengkap. Kedua sub kriteria tersebut mempengaruhi pemilihan alternatif penanganan perkerasan Jalan di Provinsi Banten. Kedua item tersebut adalah Jalan Pendekat (Oprit) (E1), Dinding Penahan Tanah (E2). Selanjutnya dihitung bobot tiap sub kriteria menggunakan bantuan software Expert Choise dan dihasilkan bobot sebagai berikut:

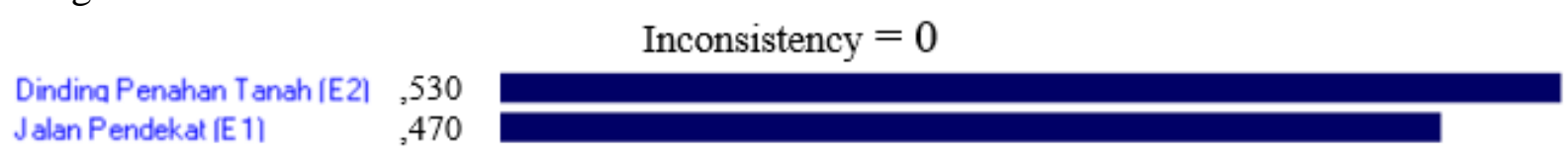

Gambar 7. Bobot dan Nilai Consistency Ratio Untuk Kriteria Aspek Perlengkapan Jalan

Berdasarkan gambar di atas, dari hasil analisis AHP Nilai CR (Pada Lampiran 3) bobot dan nilai consistency ratio untuk matrix banding berpasangan untuk sub kriteria berdasarkan kriteria aspek Bangunan pelengkap didapatkan nilai CR 0,00, berarti matrik dari kriteria tersebut dikatakan konsisten, karena nilai CR < 10\%. Gambar IV.11 juga menunjukkan bahwa kriteria Dinding Penahan Tanah memiliki bobot tertiggi dibandingkan anak kriteria lainnya yaitu sebesar 0,53 $(53 \%)$.

\section{F. Aspek Pengendalian Tanaman}


Terdapat dua sub kriteria dalam aspek Pengendalian Tanaman. Kedua sub kriteria tersebut mempengaruhi pemilihan alternatif penanganan perkerasan Jalan di Provinsi Banten. Kedua item tersebut adalah Bebas dari tumbuh-tumbuhan di sekitar (F1), Ketinggian Tumbuh tumbuhan (F2). Selanjutnya dihitung bobot tiap sub kriteria menggunakan bantuan software Expert Choise dan dihasilkan bobot sebagai berikut:

Bebas dari tumbuhan di sekitar (F1) ,531

Ketingaian Tumbuh Tumbuhan (E 2) , ,469

\section{Inconsistency $=0$}

Berdasarkan gambar di atas, dari hasil analisis AHP Nilai CR (Pada Lampiran 3) bobot dan nilai consistency ratio untuk matrix banding berpasangan untuk sub kriteria berdasarkan kriteria aspek Pengendalian Tanaman didapatkan nilai CR 0,00, berarti matrik dari kriteria tersebut dikatakan konsisten, karena nilai CR $<10 \%$. Gambar IV.12 juga menunjukkan bahwa anak kriteria "Bebas dari tumbuh - tumbuhan di sekitar" memiliki bobot tertiggi dibandingkan anak kriteria lainnya yaitu sebesar $0,531(53,1 \%)$. Pekerjaan pemeliharaan pengentalian tanaman yaitu memebersihkan lokasi sepanjang jalan bebas dari tanaman untuk memperbaiki penampilan di dalam atau di samping jalan atau memeperbaiki jarak pandang pada tikungan selama periode pelaksanaan (Spesikasi Umum 2018 KemenPUPR).

\section{KESIMPULAN DAN SARAN}

\section{Kesimpulan}

Berdasarkan analisis yang telah dilakukan bisa diambil kesimpulan yaitu:

a. Bobot aspek dalam prioritas penentuan aspek dari yang terpenting sampai yang terlemah dalam pekerjaan long segment pada jalan raya adalah Aspek Drainase dengan bobot terbesar yaitu 0,244, Aspek Perkerasan Jalan dengan bobot 0,233, Aspek Bahu Jalan dengan bobot 0,147, Aspek Bangunan Pelengkap dengan bobot 0,144, Aspek Pengendalian Tanaman dengan bobot 0,117, dan Aspek Perlengkapan Jalan dengan bobot 0,115.

b. Melalui analisis yang dilakukan maka ditemukan kriteria terpenting dari aspek - aspek yang ditinjau adalah:

- Aspek Perkerasan Jalan: (A1) Lubang; dengan bobot 0,215 (21,5\%)

- Aspek Bahu Jalan: (B3) Amblas; dengan bobot 0,269 (26,9\%)

- Aspek Drainase: (C1) Semua Jenis Saluran; dengan bobot 0,591 $(59,1 \%)$

- Aspek Perlengkapan Jalan: (D3) Pagar Keselamatan Jalan; dengan bobot 0,353 (35,3\%)

- Aspek Bangunan Pelengkap: (E2) Dinding Penahan Tanah; dengan bobot 0,53 (53\%)

- Aspek Pengendalian Tanaman: (F1) Bebas Dari Tumbuhan Sekitar; dengan bobot 0,531 $(53,1 \%)$

Berdasarkan hasil analisis ditemukan dalam pekerjaan long segment pada jalan raya, aspek terpenting yang harus diperhatikan adalah Aspek Drainase, dan pada pekerjaan drainase perlu memperhatikan lancaranya pekerjaan Semua Jenis Saluran yang dibuat dalam pekerjaan drainase.

\section{Saran}

Saran yang bisa diberikan melalui analisis ini adalah: 
a. Dalam pekerjaan - pekerjaan yang telah di analisis dalam penelitian ini menggunakan analisis AHP, perlu dilakukan sesuai dengan skala prioritas yang telah ditemukan.

b. Dalam pelaksanaannya, prioritas aspek dan kriteria pekerjaan long segment perlu disosialisasikan terhadap pihak - pihak yang terlibat dan berkepentingan agar tidak ada konflik kepentingan diantar pihak

c. Pekerjaan pemelihaaran kinerja drainase jalan yang bertujuan agar sistem drainase jalan eksisting berfungsi dengan baik sesuai kinerja yang di syaratkan maka perlu anggaran tambahan pembiayannya.

d. Bila penelitian ini digunakan sebagai acuan penelitian lain, baiknya kriteria ditambahkan dengan aspek politik dunia kerja untuk menentukan kepentiangan aspek kemanusiaan dan birokrasi lapangan.

e. Perlu dianalisis lebih lanjut setelah penerapan pekerjaan long segment terhadap responden melibatkan Pihak Kepolisian dan Dinas Perhubungan Darat .

\section{REFERENSI}

Azis, S., Putranto, E., H., D., Pranoto, R. (2014). Analisa Skala Prioritas Dengan AHP Untuk Pengalokasian Dana Pemeliharaan Jalan, Jurnal Info Manajemen Proyek Vol 5 September 2014

Elviany. (2015). Identifikasi Kreteria Teknis Penyusunan Ruas Jalan Prioritas Dengan Metode AHP. Program Pasca Sarjana Magister Teknik Sipil Universitas Tarumanagara

Kustamar, Putranto, E., H., D., Anita. (2014). Penentuan Skala Prioritas Pemeliharaan Berkala Jalan di Kabupaten Malang. Jurnal Info Manajemen Proyek Vol 5 September 2014

Saaty, T.L. (1993), Pengambilan Keputusan (Cetakan Ke II), PT. Pustaka Binaman Presindo. Jakarta Sugiyono, 2006, Statistika untuk Penelitian, Cetakan ke sembilan, CV Alfabeta, Bandung

Saaty, T.L. (2012), Methods,Concepts and Applications of the Analytic Hierarchi Process, second edition

Undang - Undang no.22 tahun 2009 tentang Lalu Lintas dan Angkutan Jalan

Undang-undang nomor 38 tahun 2004 tentang Jalan 
INDIKATOR KINERJA JALAN LONG SEGMENT DI BANTEN

Novel Ridwan, et.al

DENGAN ANALISIS ANALYTICAL HIERARCHY PROCESS 